\title{
An Interview with Douglas Ulmer
}

\section{Rachel Crowell}

This is an edited version of an interview with Douglas Ulmer, whose initial two-year term as AMS Treasurer began on February 1, 2021. Ulmer is a professor at the University of Arizona. The interview was conducted in fall 2020 by freelance writer Rachel Crowell.

Notices: When and how did you first discover your passion for mathematics and its community?

Ulmer: Already in elementary school, I enjoyed mathematics and seemed to be good at it. That continued through high school, so math was on my short list of options for a college major (some of the other options being comparative literature, philosophy, and music). My first real experiences of a mathematics community came later in graduate school. I'm happy that many departments are now taking more of an interest in building community among their undergraduate majors, and I think this will help inspire more students to persist in the degree and perhaps even go further in mathematics.

Notices: You work in algebraic geometry and number theory. What excites you about working in those fields?

Ulmer: I have always enjoyed the precision and structure of algebra, and I've also always enjoyed geometry (I'm a bit of a visual thinker), so their combination as algebraic geometry has been a passion since I first learned a bit about it in college. Most of my work in number theory has been in a subfield called "arithmetic algebraic geometry" which recasts number-theoretical questions in ways that make them amenable to geometric (or geometry-inspired) solutions. The other cool thing about number theory is that it brings

Rachel Crowell is a freelance math and science writer whose email address is rache1jcrowe11@gmai1. com.

For permission to reprint this article, please contact: reprint-permi ssion aams.org.

DOI: https://dx.doi.org/10.1090/noti2229

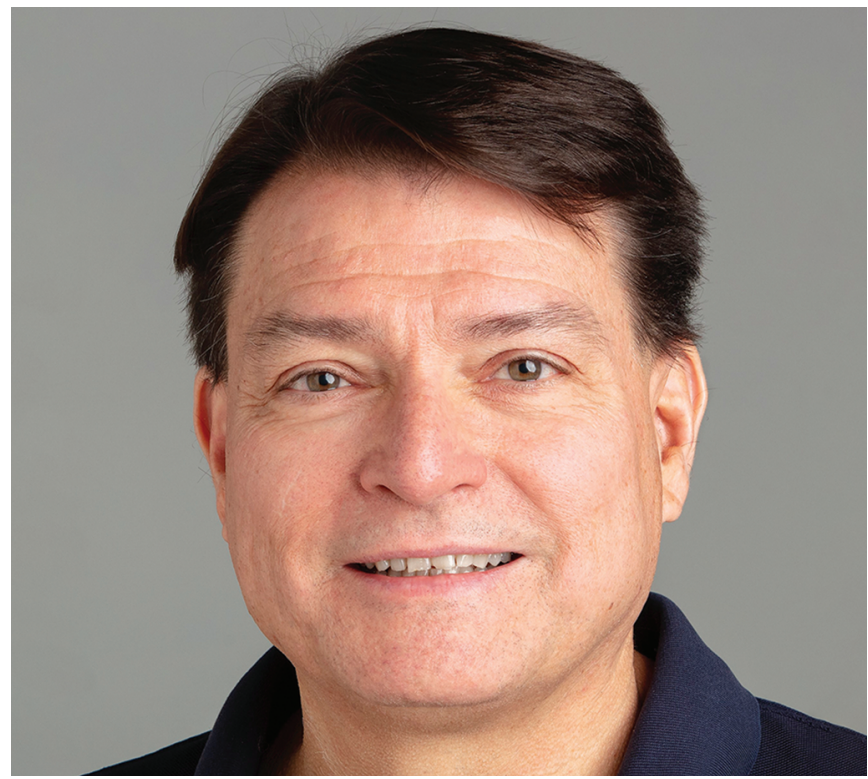

Figure 1. AMS Treasurer Douglas UImer.

in tools from absolutely every corner of mathematics. It's fun to see that and sometimes to use unexpected bits of math yourself.

Notices: What's an example of a time that you used unexpected bits of math?

Ulmer: I have recently had occasion to use Fourier series and a hard theorem about real analytic functions in papers about number-theoretic questions. 
Notices: What are some key ideas or questions you have been exploring lately?

Ulmer: Whenever you have an algebraic curve (the solution set of a two-variable polynomial equation) you get a fancier gadget called its Jacobian. The Jacobian is usually of dimension greater than one (so in some sense is more complicated than your original curve), but it has extra structures (like a group law) that are powerful tools for studying the original curve. I've been thinking about some of those extra structures (the $p$-torsion subscheme of the Jacobian) for curves over fields of characteristic $p$ and also how these Jacobians break up into direct sums (the decomposition into simple factors up to isogeny) for curves over the complex numbers with extra symmetries.

Notices: Why did you decide to apply for the position of Treasurer of the AMS?

Ulmer: A member of the search committee approached me about applying and I thought the position would be interesting and a good way to serve the profession in a national role.

Notices: What do you see as some of the key assets the AMS offers to the mathematical community?

Ulmer: The list is very long! For young mathematicians, I think the program of meetings is very important as a forum to present their work and to build their professional networks. The journal and book programs are of very high quality and fairly priced. The policy committees think through complicated issues and make recommendations on important questions around education, climate and diversity, professional ethics, human rights, and science policy. And the Society advocates for the field and for funding to support our research from NSF and other agencies. Finally, MathSciNet is an indispensable tool for every working mathematician. There are others, but these are the big things.

Notices: An announcement about your appointment described you as a longtime member of the AMS. About how long have you been a member?

Ulmer: Graduate students were given free affiliate memberships when I started my PhD in 1983 and I have been a member almost continuously since then.

Notices: What major changes have you seen in the mathematics community, both within and outside of the AMS, over your career?
Ulmer: There are more women studying mathematics and more women in faculty positions (although still not nearly the same representation in senior positions). There is greater geographic dispersion of excellent mathematicians. There are more and deeper interactions with areas of science beyond physics, and people seem to be more relaxed about "pure" versus "applied." A larger fraction of university mathematicians appreciate that fostering success among the students we have (versus the students we wish we had) is key to the future of the profession and the future of science.

Notices: What do you think is driving the greater geographic dispersion of excellent mathematicians?

Ulmer: There are more universities with research ambitions outside the traditional centers, so more expectations for faculty research and more well-trained PhDs to do this research.

Notices: What do you think is driving the change in perspective you mentioned regarding pure and applied math?

Ulmer: We've seen more applications of mathematics that were previously thought to be absolutely pure, for example, applications of number theory to cryptography, applications of algebraic geometry to information transmission and other aspects of computer science, and applications of combinatorics to biology.

Notices: Can you expand on the point you made earlier about more mathematicians appreciating "that fostering success among the students we have (versus the students we wish we had) is key to the future of the profession and the future of science"? What do you mean?

Ulmer: There are at least two aspects to this. On one hand, there has been significant democratization of higher education. This is great, but it means that we have to be ready to help students from a much broader range of backgrounds succeed. And on the other, there is a much bigger demand for mathematically sophisticated workers, so we can't afford the old "look to the right, look to the left, one of you won't be here next term" approach that fails a large fraction of students.

Notices: In what ways have you seen public perceptions of math change?

Ulmer: There is greater recognition among the public that the mathematical sciences have a big impact (potentially positive or negative) on our quality of life via things like secure communications, data science, and pandemic modeling. 
Notices: What are you most looking forward to about this position?

Ulmer: I was looking forward to regular visits to Providence (I was a graduate student at Brown University), Ann Arbor, and Chicago, but that is not in the cards for the moment! I also look forward to working with the volunteer leaders and staff of AMS, a very interesting, accomplished, and dedicated group of people.

Notices: What first inspired you to get involved with leadership in the AMS?

Ulmer: I have benefited a lot from the AMS over my career, especially from the program of meetings, the journals, and the policy committees. It seems fitting to try to help keep the organization healthy and thriving for the next generation.

Notices: Have you held other leadership positions with the AMS?

Ulmer: No, but I have held other leadership roles outside of the AMS, like Southwestern Center cofounder and director, director of graduate studies, and department head/chair.

Notices: What does acceptance of this position mean to you?

Ulmer: I'm honored! It's an opportunity to help an organization with a long and distinguished history and a bright future. Of course, I hope to have some fun at the same time.

Notices: How has the AMS been faring financially during the COVID-19 pandemic?

Ulmer: Pretty well overall. Revenues have been reduced, especially due to meetings being moved online, but expenses have also been reduced. The staff in Providence have done a great job of adapting to these challenges and moving the whole operation to the internet and it looks like we will have a small positive bottom line for 2020. No doubt 2021 will be challenging, but I think we are well prepared.

Notices: What steps do you think can be taken to ensure its continued success throughout the rest of the pandemic and into the economic recovery period?

Ulmer: I think the main challenges for the AMS were there before the pandemic and will be there, perhaps reinforced, after: we need to remain relevant to potential members, adapt to new challenges in publishing, and make sure our endowment is wisely managed.

Notices: What would you say to young mathematicians about the importance of investing-with membership dues and their

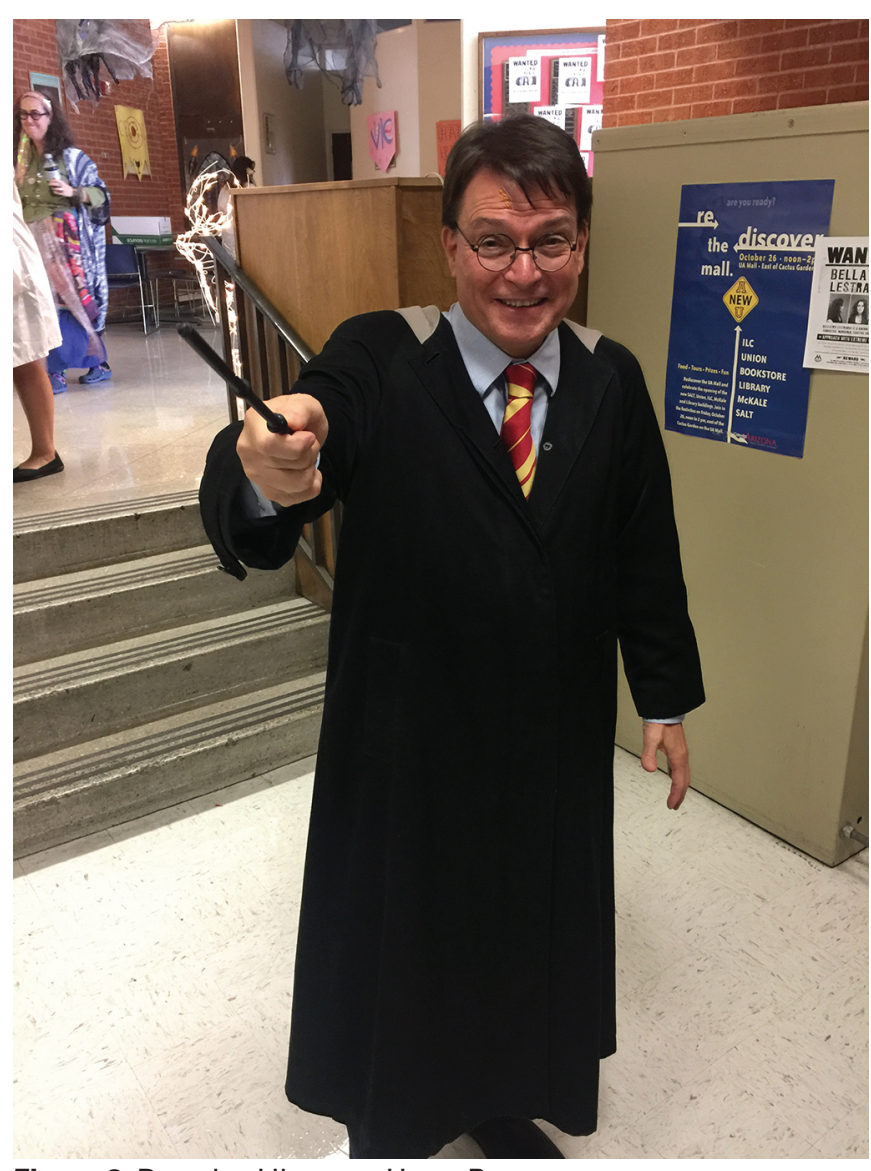

Figure 2. Douglas Ulmer as Harry Potter.

time-in professional organizations such as the AMS during a time when many folks are stretched thin with responsibilities and financial pressures?

Ulmer: First, I'd say that if you've decided that mathematics is your life's work, then what better place to invest some energy and effort than the main organization that advocates for the field?

Regarding our current difficulties, I acknowledge that they are daunting, but we have faced serious challenges before (energy crises, wars and terrorist attacks, financial crashes...), we face many now (the pandemic, racism and inequality, climate change), and there will be others we haven't even imagined yet. All that said, mathematics endures as one of the most significant areas of human accomplishments and one of the most important areas of continuing investigation. It's worth doing, and it's worth advocating for, so the AMS is worth supporting.

Notices: In "A Word from Jane Hawkins" published in April 2020, Hawkins mentioned that "the AMS has not been earning enough to completely cover its costs, but luckily money is added in annually from the interest on the endowment, and that makes up the difference." Are you concerned about that? 
Ulmer: I would come at this from a different angle. Some of the activities of the AMS, like books, journals, and MathSciNet, "pay for themselves" (i.e., generate revenue that covers their costs). Others, like meetings, Math Research Communities, and lobbying for research support, do not. We're fortunate to have a healthy endowment, and the income from it allows the AMS to offer more programs and services than it would be if it were supported solely by the publishing activities.

The AMS publishes financial accounts in the Report of the Treasurer (the last was in the December 2020 Notices), so anyone interested can see the details there. In very round numbers, the AMS currently spends about $\$ 30 \mathrm{M}$ per year on its activities, and about $\$ 6 \mathrm{M}$ of that comes from income on the endowment.

Notices: For how long can the interest on the endowment make up for this?

Ulmer: With proper management, the endowment will provide similar levels of support in perpetuity. (In this regard, it is like a university endowment, albeit a lot smaller!) If, as we hope and expect, donors continue to support the AMS with further donations, we could expect a larger contribution to the operations of the AMS in the future.

Notices: What do you see as some of your biggest priorities as the new Treasurer?

Ulmer: I mentioned that income from the endowment is a major resource for the AMS. I'd like to foster a more disciplined approach to deciding what we invest in and when, why and how we change those allocations. I'm not suggesting a wholesale change in policies, but rather making our investments a bit more resilient to financial crises and adapted to the increasingly important role they play in funding our activities.

Notices: What are some of the other things you want to accomplish?

Ulmer: Another really important issue for the Treasurer and the other trustees is to adapt the AMS to the needs of its current and future membership. Many professional societies are facing reduced interest in membership and although the AMS is doing pretty well in this regard, we can't be complacent.

Finally, the nature of publishing is changing (think open access journals, arXiv, and e-books and the vast amount of information available via a quick Google search). Adapting to and even leading change in these areas will be important.
Notices: Are there any words you would like to share about the significance of your predecessor's contributions as Treasurer since 2011?

Ulmer: Jane Hawkins was Treasurer for ten years and she was tremendously effective. She oversaw a more than doubling of the Society's assets, she helped ensure that the income from those assets was used effectively, and she was a wise and measured voice on the Board of Trustees. She will be a hard act to follow!

Notices: What are some of the things you enjoy doing when you're not doing math?

Ulmer: I like to cook quite a variety of things, with most of my favorites coming from various cultures around the Mediterranean; France and Italy of course, but also Spain, Turkey, Lebanon, and Morocco.

I enjoy music, mainly jazz greats like Coltrane, Monk, Sonny Rollins, Dexter Gordon, etc., but also classical music and 70s soul. I played saxophone and had a band in college. Earlier in life, I wanted to be a jazz musician, but that is a much more difficult way to make a living than proving theorems!

I also enjoy traveling a lot, or rather I did before the pandemic, and I'm looking forward to being able to do so again soon.

\section{Credits}

Figure 1 is courtesy of Steven Meckler. Figure 2 is courtesy of Douglas Ulmer. 